\title{
MicroRNA-204 plays a role as a tumor suppressor in Newcastle disease virus-induced oncolysis in lung cancer A549 cells
}

\author{
YING LIANG $^{1 *}$, WEN-YU TIAN $^{2 *}$, JUAN-JUAN HUANG $^{1 *}$, LING-XI GAO $^{1}$ and XIAO-HUI FAN ${ }^{1}$ \\ ${ }^{1}$ Department of Microbiology, School of Preclinical Medicine, Guangxi Medical University, Nanning, \\ Guangxi Zhuang Autonomous Region 530021; ${ }^{2}$ Department of Clinical Laboratory, \\ Tianjin Children's Hospital, Tianjin 300000, P.R. China
}

Received July 3, 2020; Accepted March 26, 2021

DOI: $10.3892 / \mathrm{ol} .2021 .12743$

\begin{abstract}
Tumor development and progression are closely associated with various microRNAs (miRNAs/miRs). We have previously shown that Newcastle disease virus (NDV) strain 7793 induces oncolysis in lung cancer. However, how NDV exerts its oncolytic effect on lung cancer remains to be investigated. The present study assessed the role of miR-204 in the NDV-induced oncolysis of lung cancer A549 cells by oncolysis induction in vitro. miR-204 was significantly upregulated in NDV-treated A549 cells. Overexpression or inhibition of miR-204 was significantly associated with NDV-induced oncolysis in A549 cells. Caspase-3 and Bax, major regulators of the apoptosis pathway, were regulated by miR-204, and the association between caspase-3-related apoptosis and miR-204 was identified in NDV-mediated oncolysis. These data demonstrated that miR-204 as a tumor suppressor played a role in NDV-induced oncolysis in lung cancer cells. The present study demonstrates the potential of strategies using miRs to improve oncolytic NDV potency, and highlights miR-204 as a tumor suppressor in NDV-induced oncolysis of lung cancer cells.
\end{abstract}

\section{Introduction}

Lung cancer is a common malignancy, ranking first among all causes of cancer-related mortality worldwide, with a 5 -year survival rate of $<20 \%$ (1). There has been significant progress in lung cancer molecular targeted therapies, such as small-molecule inhibitors targeting molecular aberrations, such as epidermal growth factor and anaplastic lymphoma kinase,

Correspondence to: Professor Xiao-Hui Fan, Department of Microbiology, School of Preclinical Medicine, Guangxi Medical University, 22 Shuangyong Road, Nanning, Guangxi Zhuang Autonomous Region 530021, P.R. China

E-mail: fanxiaohui63@163.com

*Contributed equally

Key words: Newcastle disease virus, A549, microRNA, lung cancer, oncolysis during recent years (2). However, the prognosis of patients with advanced lung cancer remains poor $(2,3)$. Viral therapy, using oncolytic viruses, eliminating neoplasms through cell lysis and death mechanisms, is urgently required as one of the novel treatment strategies. The avian paramyxovirus Newcastle disease virus (NDV) possesses antitumor activity and is safe for the host $(4,5)$, as demonstrated in animal models and several phase II clinical trials (6-8). Numerous investigations have been conducted into the antitumor mechanisms of NDV, including its ability to stimulate immunoreactive cells and to induce tumor cell death (9-13). The latter has been called the oncolytic effect of NDV, and involves multiple tumor cell death mechanisms (14). However, how NDV exerts its oncolytic effect on lung cancer remains to be investigated.

MicroRNAs (miRNAs/miRs) are non-coding small RNA molecules that regulate gene expression after transcription, and thus affect numerous biological processes, including cell proliferation, differentiation, development and apoptosis. In recent years, the involvement of miRNA in the regulation of tumor cell apoptosis through post-transcriptional regulation of cascade signaling pathways has been revealed (15). Therefore, combined with NDV-induced tumor cell death, we hypothesized that miRNAs play a regulatory role as tumor suppressors in the NDV-induced oncolysis of tumor cells. miR-204 as a tumor suppressor plays an important role in various types of cancer cells, including lung cancer cells (16). Additionally, miR-204 expression is downregulated in non-small cell lung cancer (17). In the present study, the role of miR-204 in the promotion of NDV-induced oncolysis of lung cancer A549 cells is described. The study assessed whether overexpression or inhibition of miR-204 was significantly associated with NDV-induced oncolysis in A549 cells, and also investigated whether major regulators of the apoptosis pathway were regulated by miR-204. The study evaluated whether miR-204 plays a role as a tumor suppressor in NDV-induced oncolysis in lung cancer cells.

\section{Materials and methods}

Cell lines and virus. The human lung cancer A549 cell line were maintained in Ham's F-12 medium (Kaign's modification) supplemented with $10 \% \mathrm{FBS}, 100 \mathrm{U} / \mathrm{ml}$ penicillin and $100 \mu \mathrm{g} / \mathrm{ml}$ streptomycin (all Gibco; Thermo Fisher Scientific, Inc.). The cells were cultured at $37^{\circ} \mathrm{C}$ in a $5 \% \mathrm{CO}_{2}$ incubator. 
NDV strain 7793 was obtained from the laboratory in the Department of Microbiology of Guangxi Medical University (Nanning, China). A stock of infectious virus was propagated in embryonated chicken eggs. The allantoic fluid was collected from the eggs and centrifuged (300-400 x g for $30 \mathrm{~min}$ at $4^{\circ} \mathrm{C}$ ), and then subjected to ultracentrifugation $(50,000 \mathrm{x} \mathrm{g}$ for $60 \mathrm{~min}$ at $\left.4^{\circ} \mathrm{C}\right)$. The pellet was resuspended in phosphate-buffered saline (PBS) and purified twice using a $35 \%$ sucrose gradient and ultracentrifugation (97,000 $\mathrm{xg}$ for $60 \mathrm{~min}$ at $4^{\circ} \mathrm{C}$ ). Purified virus was resuspended in PBS containing 0.1\% EDTA. NDV titers were determined using hemagglutination tests, with a single hemagglutination unit (HU) defined as the lowest virus concentration leading to visible agglutination of chicken erythrocytes. The ultraviolet (UV)-NDV 7793 was produced by inactivating NDV 7793 with UV light for $30 \mathrm{~min}(254 \mathrm{~nm}$; $\left.2 \mathrm{~mW} / \mathrm{cm}^{2} ; 30 \mathrm{~cm}\right)$.

A549 cell culture with NDV or $U V-N D V$ in vitro. A549 cells $\left(1 \times 10^{5}\right)$ were seeded in 6 -well plates until reaching $80-90 \%$ confluency in triplicate. Prior to culture with virus, the cells were washed twice with PBS. The A549 cells were cultured with NDV 7793 (25 HU/10 ${ }^{5}$ cells) or UV-NDV 7793 (25 HU/10 $0^{5}$ cells) at $37^{\circ} \mathrm{C}$ with $5 \% \mathrm{CO}_{2}$ and were collected at 24, 48 and $72 \mathrm{~h}$. As the positive control, A549 cells were cultured with $20 \mathrm{mg} / \mathrm{l}$ cisplatin (Sigma-Aldrich; Merck KGaA). As the negative control (NC), A549 cells were mock-cultured in parallel and processed in the same way. Cells were collected by centrifugation (300-400 x g for $10 \mathrm{~min}$ at $4^{\circ} \mathrm{C}$ ), washed twice in PBS and used in western blotting, reverse transcription- quantitative PCR, apoptosis and cytotoxicity assays.

All experiments using living virus and cell culture were conducted in biosafety level-2 containment of the Department of Microbiology of Guangxi Medical University and were approved by Guangxi Nanning Health Committee (protocol no. 00003).

Cytotoxicity assays. Cell Counting Kit-8 (CCK-8) (Dojindo Molecular Technologies, Inc.) was used according to the manufacturer's instructions to measure the viability and proliferation of cells. A549 cells $\left(1 \times 10^{5}\right)$ were treated with various titers of NDV (64, 128, 256, 512, 1024 and $2048 \mathrm{HU})$ and incubated for 24,48 and $72 \mathrm{~h}$ at $37^{\circ} \mathrm{C}$. Subsequently, $10 \mu \mathrm{l} \mathrm{CCK}-8$ solution was added to each well and incubated for $2 \mathrm{~h}$ at $37^{\circ} \mathrm{C}$. The absorbance was measured at $450 \mathrm{~nm}$ using a microplate reader. Cell viability was calculated using the following formula: Cell viability $=(\mathrm{OD}$ of control - OD of treatment $) /(\mathrm{OD}$ of control OD of blank) $x$ 100. The assay was repeated 3 times.

NDV-triggered oncolysis in tumor cells was analyzed using an Annexin V-fluorescein isothiocyanate (FITC) Apoptosis Detection kit containing PI (Becton-Dickinson and Company) in accordance with the manufacturer's instructions. Briefly, $1 \times 10^{6}$ cells were washed with cold PBS twice, and re-suspended in $300 \mu \mathrm{l}$ binding buffer. After incubation with $3 \mu \mathrm{l}$ Annexin V-FITC at room temperature for $10 \mathrm{~min}$ in the dark, the cells were mixed with $200 \mu$ l binding buffer prior to flow cytometry using a FACSVerse flow cytometer (BD Pharmingen; BD Biosciences). The data were analyzed using ModFit LT (version 2.0; Verity Software House, Inc.) to determine cell distribution. Results are presented as means from triplicate cultures.
One Step TUNEL Apoptosis assay kit (Beyotime Institute of Biotechnology) was used according to the manufacturer's instructions to measure the apoptosis of cells. Briefly, $1 \times 10^{5}$ A549 cells were immobilized with $4 \%$ paraformaldehyde for $30 \mathrm{~min}$ at room temperature and permeabilized using $0.2 \%$ Triton $\mathrm{X}-100$. The TdT reaction mixture $(100 \mu \mathrm{l})$ was prepared according to the manufacturer's instructions and applied to cells for $1 \mathrm{~h}$ at $37^{\circ} \mathrm{C}$ in the dark. After sealing with anti-fluorescence quenching sealing solution, the films were observed under a fluorescence microscope (EVOS FL; Thermo Fisher Scientific, Inc.). The cells in five random fields (magnification, x100) were counted.

Cytopathic assays. In brief, for cell cytopathic assays, $1 \times 10^{5}$ A549 cells were seeded in 6-well plates until reaching 80-90\% confluency in triplicate. Prior to culture with virus, the cells were washed twice with PBS. The A549 cells were cultured with NDV 7793 (25 HU/10 cells) at $37^{\circ} \mathrm{C}$ with $5 \% \mathrm{CO}_{2}$ for 24, 48 and 72 h. For the negative control (NC), A549 cells were treated with PBS in parallel and processed in the same way. Finally, cells in each group were captured using a light microscope with a green filter (magnification, x100) and six areas were randomly selected to be captured.

Transfection and RT-quantitative PCR analysis. A549 cells were seeded in 6 -well plates at $1 \times 10^{5}$ cells $/ \mathrm{ml} /$ well 1 day before the transfection. On the following day, transfection was performed when the cells had reached $\sim 70 \%$ confluence. miR-204 mimics and inhibitors were purchased from GenePharma (Shanghai, China) and the sequences for these are shown in Table I. The NCs used for the mimic and inhibitor were non-targeting sequences. The final concentration of miRNA used was $50 \mathrm{nM}$. Transfections were conducted with Lipofectamine $^{\mathrm{TM}} 3000$ (Invitrogen; Thermo Fisher Scientific, Inc.) according to the manufacturer's instructions. The transfection medium was replaced 4-6 h after transfection. Cells were cultured at $37^{\circ} \mathrm{C}$ and collected $48 \mathrm{~h}$ post-transfection for subsequent experimentations.

Total RNA was extracted using a MiniBEST Universal RNA Isolation kit (Takara Biotechnology Co., Ltd.) and quantified by the NanoDrop ND-2000 (Thermo Scientific, USA). cDNA was obtained using PrimeScript ${ }^{\mathrm{TM}}$ RT reagent kit (Takara Biotechnology Co., Ltd.) according to the manufacturer's instructions. The cDNA samples were used for quantitative PCR analysis in triplicate to determine the expression levels of miR-204, caspase-3 and Bax using a QuantiFast SYBR-Green PCR kit (Qiagen, Inc.) and an ABI 7500 Real-Time PCR instrument. Primers were purchased from Sangon Biotech, Co., Ltd., and sequences are shown in Table II. The thermocycling conditions were as follows: $95^{\circ} \mathrm{C}$ for $10 \mathrm{~min}$, followed by 40 cycles at $95^{\circ} \mathrm{C}$ for $10 \mathrm{sec}, 60^{\circ} \mathrm{C}$ for $30 \mathrm{sec}$ and $72^{\circ} \mathrm{C}$ for $30 \mathrm{sec}$. miRNA expression levels were normalized to U6 expression levels and the mRNA levels of caspase- 3 and Bax were normalized to $\beta$-actin levels using the $2^{-\Delta \Delta \mathrm{Cq}}$ method (18).

Western blotting analysis. The cells were treated with $10 \mu \mathrm{l} / \mathrm{mg}$ RIPA lysis buffer (cat. no. P0013B; Beyotime Institute of Biotechnology) and centrifuged at $4^{\circ} \mathrm{C}$ at $25,000 \mathrm{x} \mathrm{g}$ for $10 \mathrm{~min}$. The protein concentration was determined using a 
Table I. Sequences of miR-204 mimics and inhibitors.

\begin{tabular}{lc}
\hline miRNA & Sense \\
\hline miR-204 mimics & 5'-UUCCCUUUGUCAUCCUAUGCCU-3' \\
Mimic-NC & 5'-UUUGUACUACACAAAAGUACUG-3' \\
miR-204 inhibitor & 5'-AGGCUUAGGAUGACAAAGGGAA-3' \\
Inhibitor-NC & 5'-CAGUACUUUUGUGUAGUACAAA-3'
\end{tabular}

Antisense

NC, negative control; miR/miRNA, microRNA.

Table II. Primers used to detect miRNA, caspase-3 and BAX expression levels with reverse transcription-quantitative PCR.

\begin{tabular}{lll}
\hline Gene & \multicolumn{1}{c}{ Forward primer } & \multicolumn{1}{c}{ Reverse primer } \\
\hline miR-204-5p & 5'-TCCCTTTGTCATCCTATGCCTAA-3' & 5'-AAGGGAAACAGUAGGAUUCGGA-3' \\
U6 & 5'-GGAACGATACAGAGAAGATTAGC-3' & 5'-TGGAACGCTTCACGAATTTGCG-3' \\
Caspase-3 & 5'-AAGGCAGAGCCATGGACCAC-3' & 5'-CTGGCAGCATCATCCACACATAC-3' \\
BAX & 5'-AGATGTGGTCTATAATGCGTTTTCC-3' & 5'-CAGAAGGCACTAATCAAGTCAAGGT-3' \\
$\beta$-actin & 5'-TGGCACCCAGCACAATGAA -3' & 5'-CTAAGTCATAGTCCGCCTAGAAGCA-3'
\end{tabular}

$\mathrm{miR} / \mathrm{miRNA}$, microRNA.

BCA Protein Assay kit (cat. no. P0009; Beyotime Institute of Biotechnology). The protein samples (50 $\mu \mathrm{g} / \mathrm{lane})$ were separated by $10 \%$ SDS-PAGE (Bio-Rad Laboratories, Inc.) and transferred to a PVDF membrane (EMD Millipore). The membrane was blocked with a $5 \%$ non-fat milk solution at room temperature for $1 \mathrm{~h}$ and subsequently incubated with the following primary antibodies at $4^{\circ} \mathrm{C}$ overnight: Mouse antibodies against full-length caspase-3 (cat. no. 9668; 1:1,000; Cell Signaling Technology, Inc.), mouse anti-Bax (cat. no. 89477S; 1:1,000; Cell Signaling Technology, Inc.) and mouse anti- $\beta$-actin (cat. no. 3700T; 1:2,000; Cell Signaling Technology, Inc.; used as an internal control). The next day, the blots were incubated at room temperature with HRP-conjugated anti-mouse IgG secondary antibody (cat. no. 7076; 1:2,500; Cell Signaling Technology, Inc.). Immunoblots were developed using an enhanced chemiluminescence detection system (Wuhan Boster Biological Technology, Ltd.) and quantified using Quantity One V4.62 software (Bio-Rad Laboratories, Inc.). $\beta$-actin was used as the loading control.

Statistical analysis. The data are presented as the mean \pm standard deviation of three independent experiments, unless otherwise shown. Data were analyzed using SPSS 22.0 (IBM, Corp.). One-way analysis of variance followed by Tukey's post hoc test was used to identify significant differences among multiple groups. An unpaired Student's t-test was used to compare two groups. $\mathrm{P}<0.05$ was considered to indicate a statistically significant difference.

\section{Results}

NDV-induced oncolysis of human lung cancer A549 cells. To evaluate the oncolytic effects of exposure of A549 cells to NDV-7793, the present study investigated whether stimulation with NDV decreased A549 cell viability in a dose-dependent manner. The apoptotic effect of A549 cells after treatment with NDV was observed. There was a marked and rapid decrease in the viability of A549 cells $48 \mathrm{~h}$ after treatment with NDV in comparison with 24 or $72 \mathrm{~h}$ of treatment, and the viability of the A549 cells after treatment with NDV at 1:2048 for $48 \mathrm{~h}$ was the lowest (Fig. 1A). The effects of NDV-induced cytopathy in A549 cells were also observed (Fig. 1B), including the appearance of A549 cell lesions after stimulation with NDV for $24 \mathrm{~h}$, a clear cytopathic effect at $48 \mathrm{~h}$ and a large number of dead cells at $72 \mathrm{~h}$. Observation under TUNEL fluorescence microscopy showed apoptotic A549 cells after exposure to NDV-7793 (Fig. 1C). After treatment with NDV, the oncolysis rate was increased compared with that in the PBS group $(\mathrm{P}<0.05)$ (Fig. 1D). Therefore, NDV induced the oncolysis of A549 cells. When NDV was inactivated by UV treatment, oncolysis was significantly but not completely decreased $(\mathrm{P}<0.05)$, which may be due to the various mechanisms of NDV-induced oncolysis. Hemagglutinin neuraminidase, as a viral envelope protein of NDV, has the ability alone to induce oncolysis (19).

Expression of miR-204 in NDV-treated A549 cells. It has been shown that miR-204 regulates apoptosis and that miR-204 is significantly downregulated in lung cancer cell lines, including A549 (20). To determine whether treatment with NDV affected the expression of miR-204, q-PCR assays were conducted to assess miR-204 expression levels in the present study. miR-204 was significantly upregulated in NDV-treated A549 cells $(\mathrm{P}<0.05)$ compared with that in control cells at 48 and $72 \mathrm{~h}$ (Fig. 2A). There was an increase in miR-204 levels $24 \mathrm{~h}$ and $48 \mathrm{~h}$ after treatment with NDV, with the peak after 72 h (Fig. 2B).

Next, the study investigated whether expression of miR-204 was significantly associated with oncolytic capacity in A549 
A

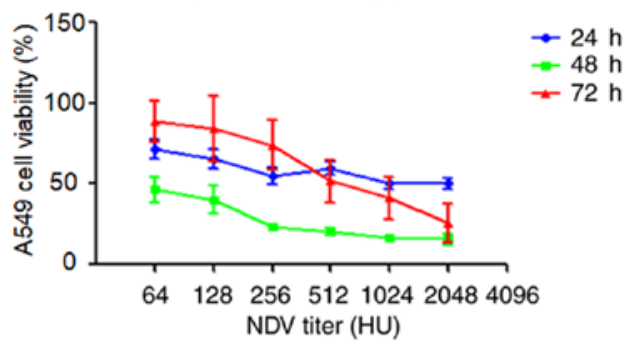

C
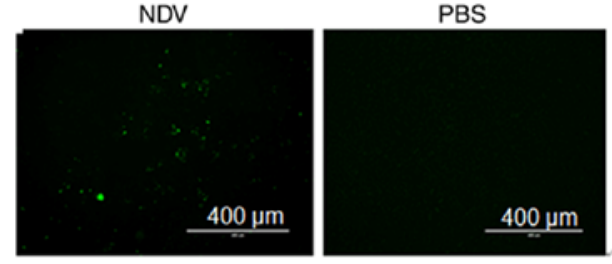

B
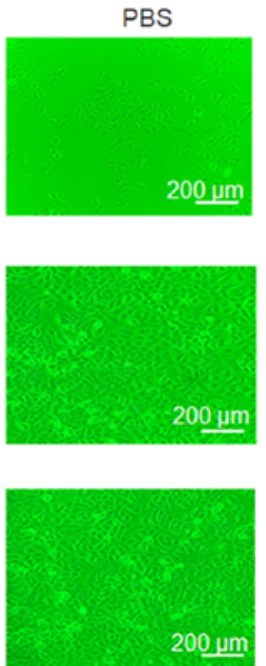
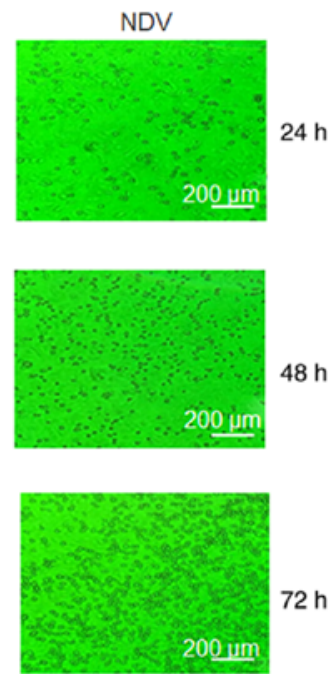

D

$24 \mathrm{~h}$
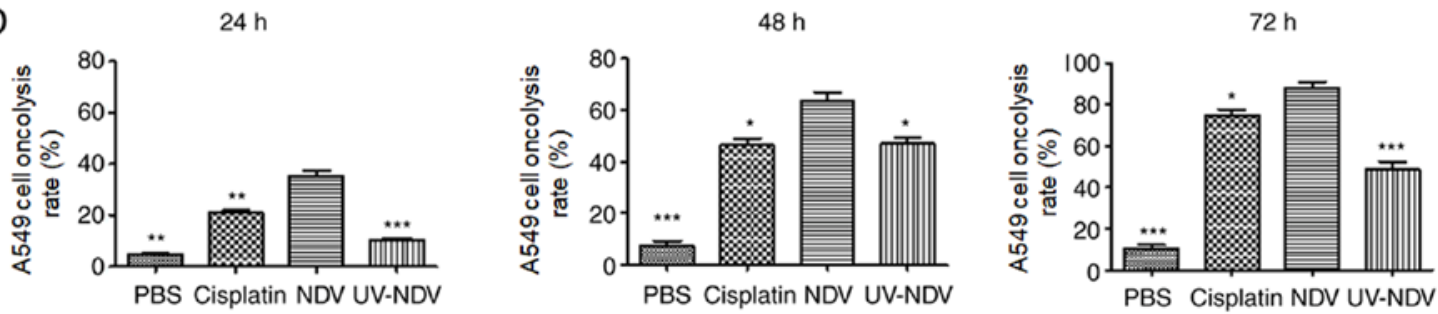

Figure 1. Oncolysis induction in NDV-stimulated human lung cancer A549 cells in vitro. (A) A549 cell viability after NDV stimulation at 24, 48 and 72 h, respectively, was detected by Cell Counting Kit-8 test. (B) NDV-induced cytopathic effect was observed through light microscopy with a green filter (magnification, x100; scale bar, $200 \mu \mathrm{m}$ ). (C) Observation under TUNEL fluorescence microscopy showed that apoptotic cells appeared when A549 cells were exposed to NDV-7793 (magnification, x100; scale bar, $400 \mu \mathrm{m}$ ). (D) Oncolysis induction in NDV-stimulated human lung cancer A549 cells in vitro was analyzed using Annexin V-fluorescein isothiocyanate. ${ }^{*} \mathrm{P}<0.05,{ }^{* *} \mathrm{P}<0.01$ and ${ }^{* * * *} \mathrm{P}<0.001$ vs. NDV. Results are representative of three independent experiments. NDV, Newcastle disease virus; UV, ultraviolet; PBS, phosphate-buffered saline.
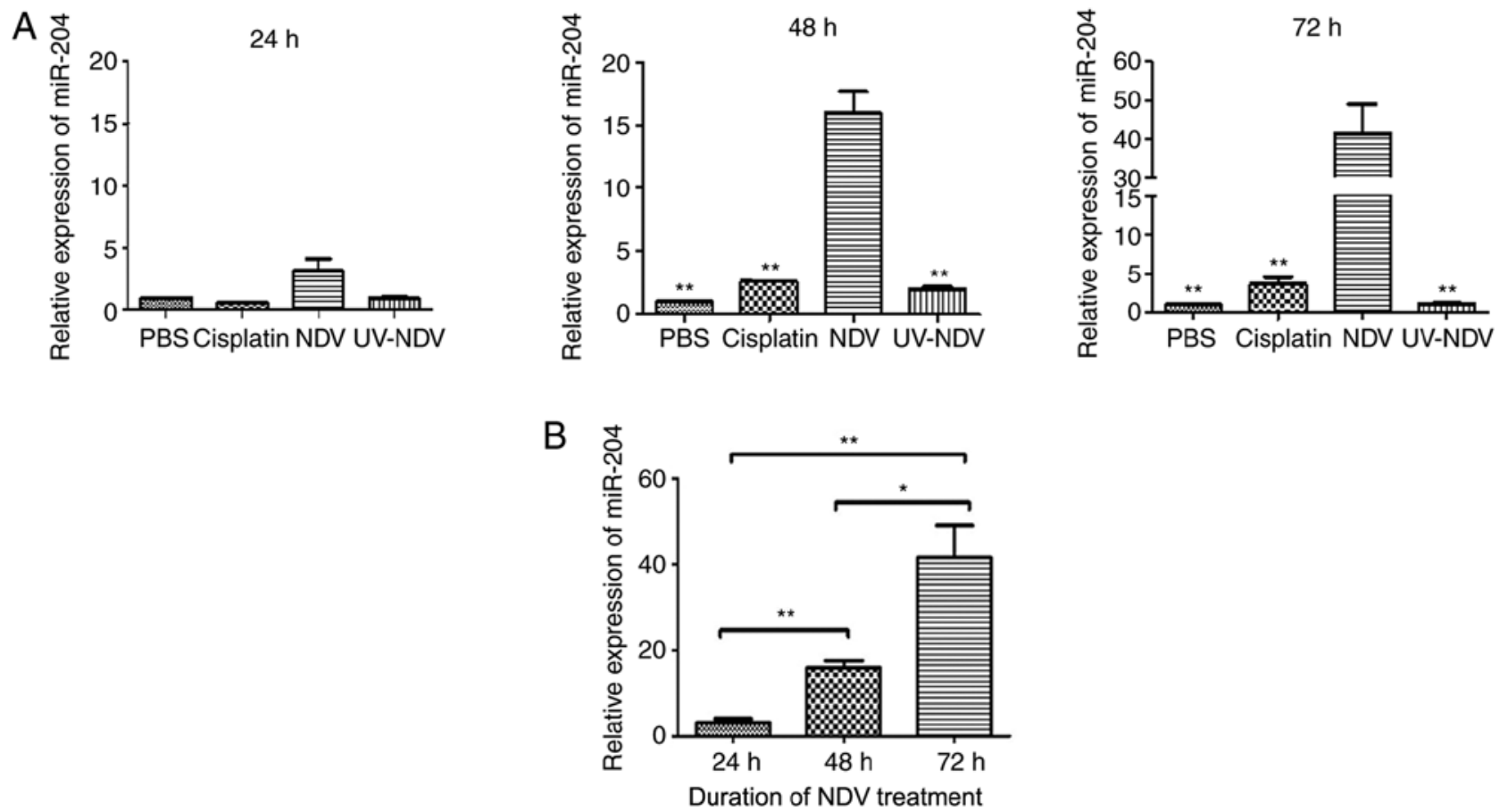

Figure 2. miR-204 expression levels in NDV-stimulated A549 cells in vitro. (A) A549 cells were incubated with NDV 7793, UV-NDV 7793 and cisplatin, respectively. Total RNA was extracted and subjected to qPCR. PBS-treated A549 cells were used as NCs. Compared with that in NCs or UV-NDV, miR-204 was significantly upregulated in NDV-treated A549 cells. ${ }^{* *} \mathrm{P}<0.01$ vs. NDV. (B) miR-204 expression levels in NDV-mediated A549 cells for 24,48 and $72 \mathrm{~h}$ were detected by qPCR. There were significant differences in the miR-204 levels of NDV-treated A549 cells. The peak increase in miR-204 levels was observed at $72 \mathrm{~h}$ after treatment with NDV. ${ }^{*} \mathrm{P}<0.05$ and ${ }^{* *} \mathrm{P}<0.01$. Results are representative of three independent experiments. NDV, Newcastle disease virus; UV, ultraviolet; PBS, phosphate-buffered saline; miR, microRNA; qPCR, quantitative PCR. 
A

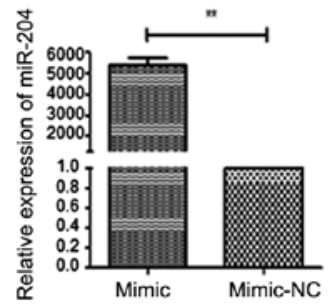

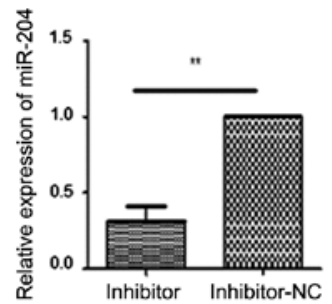

B

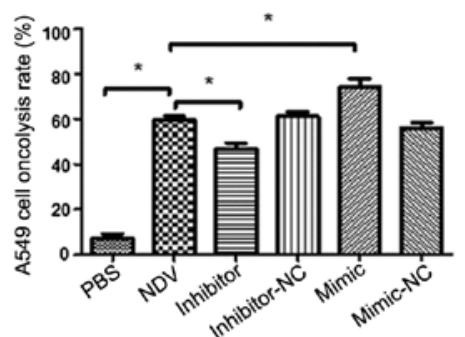

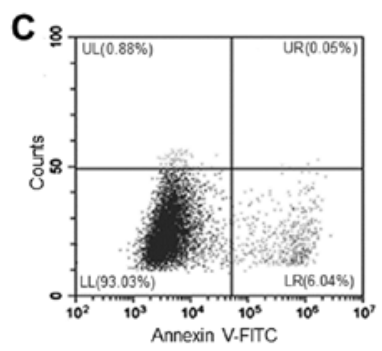

PBS

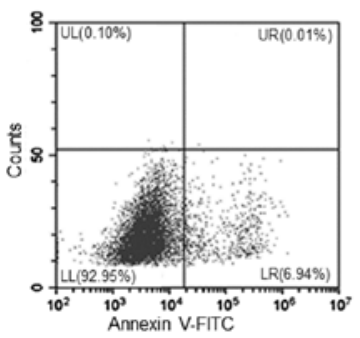

PBS

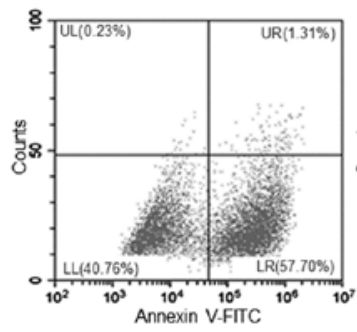

NDV

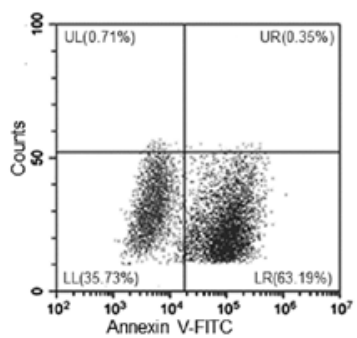

NDV

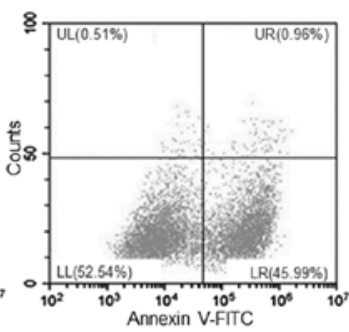

Inhibitor

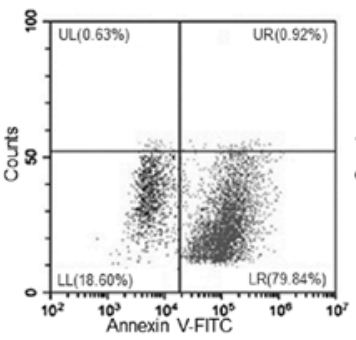

Mimic

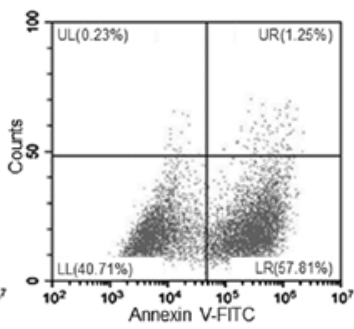

Inhibitor-NC

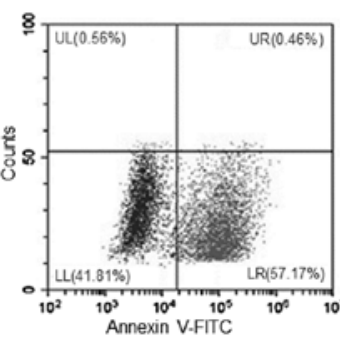

Mimic-NC

Figure 3. Overexpression and inhibition of miR-204 are significantly associated with NDV-inducted oncolysis capacity in A549 cells. (A) A549 cells were incubated with miR-204 inhibitors or mimics. Total RNA was extracted and subjected to quantitative PCR. Unstimulated A549 cells were used as NCs. miR-204 expression level was significantly increased or decreased after transfection of miR-204 inhibitors or mimics to A549 cells, respectively. ${ }^{* *} \mathrm{P}<0.01$. (B and C) The proportion of oncolysis in each group was determined using flow cytometry. Compared with that in the PBS group, the proportion of oncolysis was significantly increased in NDV-induced A549 cells. Compared with that in the NDV group, the proportion of oncolysis was significantly decreased or increased after transfection with miR-204 inhibitors or mimics, respectively. ${ }^{*} \mathrm{P}<0.05$. Results are representative of three independent experiments. NDV, Newcastle disease virus; PBS, phosphate-buffered saline; miR, microRNA; NC, negative control.

cells treated with NDV, using miR-204 inhibitors or mimics. The miR-204 expression level was significantly increased and decreased after transfection of the miR-204 inhibitor and mimic, respectively, in the A549 cells (both $\mathrm{P}<0.01$; Fig. $3 \mathrm{~A}$ ). Compared with that in the PBS group, the proportion of oncolysis was significantly increased in NDV-induced A549 cells $(\mathrm{P}<0.05$; Fig. 3B and $\mathrm{C})$. Compared with that in the NDV group, the proportion of oncolysis was significantly decreased or increased after transfection with miR-204 inhibitors or mimics, respectively $(\mathrm{P}<0.05$; Fig. $3 \mathrm{~B}$ and $\mathrm{C})$.

Association between apoptosis-related proteins and miR-204 in NDV-inducted oncolysis. To investigate whether the oncolysis pathway regulated by miR-204 was dependent on caspase-3 activity, A549 cells were incubated with miR-204 inhibitors or mimics following stimulation with NDV. A decrease in caspase-3 and Bax mRNA levels was found after treatment with the miR-204 inhibitor compared with the NC (both $\mathrm{P}<0.01$ ), while an increase in caspase- 3 and Bax was found after treatment with the mir-204 mimic (both $\mathrm{P}<0.05)$ (Fig. 4A). Similar to the mRNA results, a clear decrease in the levels of Bax and caspase-3 protein levels was also observed for NDV-stimulated A549 cells pretreated with miR-204 inhibitors compared with the $\mathrm{NC}$, while an increase in levels was found following treatment with the mimic (Fig. 4B).

\section{Discussion}

The avian paramyxovirus NDV is a single-stranded negative-sense RNA virus that causes Newcastle disease in poultry, but almost certainly does not infect mammals. NDV is almost safe for a human host and possesses tumor-selective oncolytic activity. Impairment of antiviral type I IFN signaling in tumor cells is believed to be the reason for effective tumor-selective death. The virus-selective oncolytic effect is apoptosis dependent, and related to higher levels of viral transcription, translation and progeny virus formation (21). In the present study, the effect of NDV-7793 was observed in human lung adenocarcinoma A549 cells in vitro and its therapeutic potential in lung cancer was explored. Cisplatin, the standard first-line choice of chemotherapy drugs in the clinical treatment of various types of solid cancer, such as lung and cervical cancer, and melanoma, was used as positive control in this study (22). Apoptotic A549 cells began to appear at $24 \mathrm{~h}$ after virus treatment, indicating that NDV-7793 infected the A549 cells and induced apoptosis. However, a marked and rapid decrease in the viability of A549 cells was found after $48 \mathrm{~h}$ of treatment with NDV in comparison with that at 24 or $72 \mathrm{~h}$ of treatment. We hypothesize that these unexpected results may be due to the complicated interactions between NDV and cancer cells. Depending on the severity of the clinical manifestations 
A
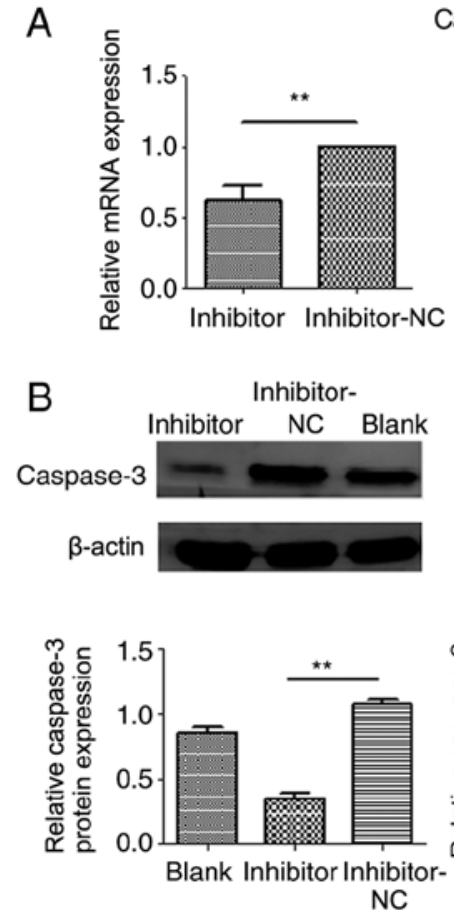

Caspase-3

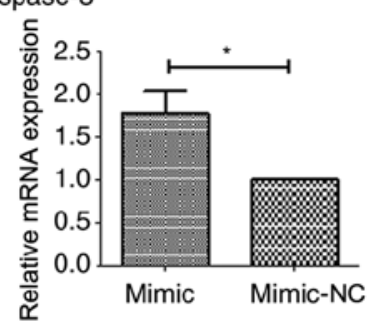

Mimic-

NC Mimic Blank

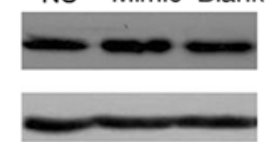

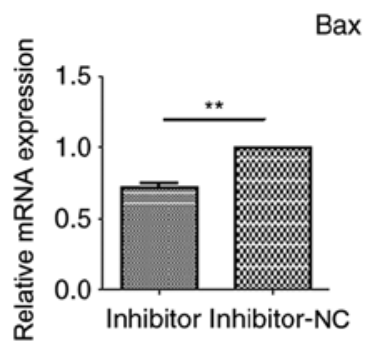
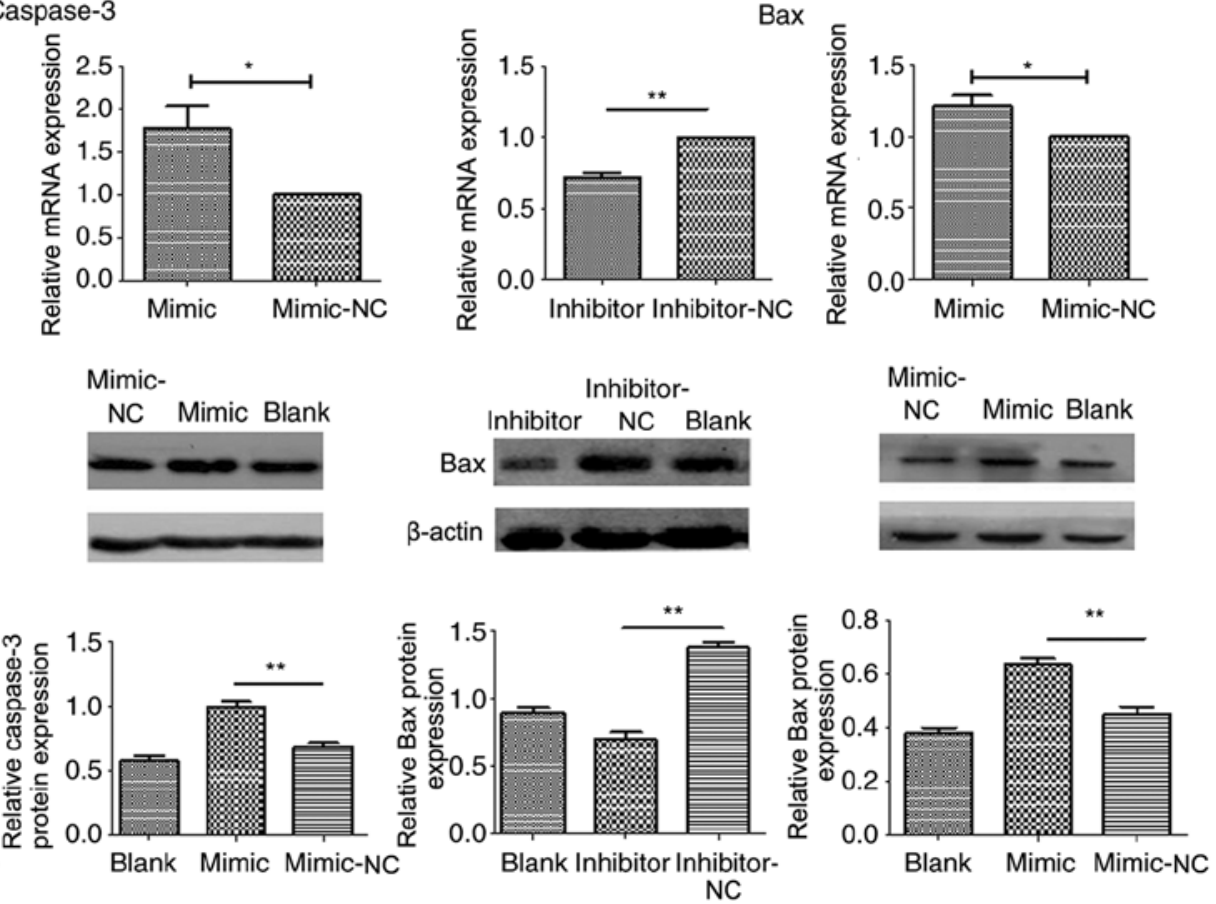

Figure 4. miR-204-regulated triggered oncolysis pathway is dependent on caspase-3 and Bax activity. A549 cells were pre-incubated with miR-204 inhibitors or mimics following stimulation with Newcastle disease virus. The expression of apoptosis-related proteins full-length caspase-3 and Bax were detected by (A) quantitative PCR and (B) western blotting analysis. The expression levels of Bax and full-length caspase-3 were upregulated. ${ }^{*} \mathrm{P}<0.05$ and ${ }^{* *} \mathrm{P}<0.01$. Results are representative of three independent experiments. miR, microRNA; NC, negative control.

observed in chickens and the tropism of the virus, NDV has been classified into the following five pathotypes: Asymptomatic enteric, lentogenic, mesogenic, viscerotropic velogenic and neurotropic velogenic (23). NDV7793 is a lentogenic strain that has low virulence or is non-virulent. The release of NDV after budding from the plasma membrane is not efficient. Therefore, the generation and release of offspring viruses is limited. From the aspect of the tumor cells in the present study, some A549 cells died after NDV treatment, and the remaining living cells continued to grow and reproduce. Therefore, this may be one of the reasons that in in vivo studies, it is necessary to infuse NDV several times to achieve a significant and sustained antitumor effect (24). In future studies, the recombinant NDV strains can be considered to make up for this deficiency. UV radiation could not completely destroy the cytotoxicity of NDV, which may be due to various mechanisms of NDV-induced cytotoxicity. Hemagglutinin neuraminidase, as a viral envelope protein of NDV, has the ability alone to induce cytotoxicity (18).

A number of NDV strains have been studied for oncolytic activity in various cancer cells (25-28). For example, the effects of NDV strain D90, which was isolated in China, against oral squamous cell carcinoma cells have been identified, and the cell death induced by D90 was apoptotic (28). The results of the present study are in agreement with those of several previous studies (25-28). However, the mechanisms that lead to this activity are unclear. In the current study, the role of miR-204 in NDV-induced oncolytic activity was described. miR-204 is closely associated with the regulation of apoptosis, proliferation and metastasis in tumor cells. For example, miR-204 inhibits the proliferation and migration of non-small cell carcinoma cells by targeting Atf2 (29). The present study examined the expression of miR-204 and explored its role in oncolytic NDV-induced apoptosis. The results suggested the existence of miR-204-dependent, NDV-induced tumor oncolytic activity. Previous studies have shown that the expression of miR-204 is significantly downregulated in a number of lung cancer cell lines, including A549. Furthermore, miR-204 overexpression induces apoptosis in lung cancer cells (16). In the present study, it was found that the expression of miR-204 was significantly upregulated when A549 cells were cultured with NDV in vitro. To examine the role of miR-204 in NDV-triggered oncolytic activity, miR-204 was overexpressed or inhibited in lung cancer A549 cells. The overexpression of miR-204 increased NDV-triggered oncolysis while inhibition via an miR-204 inhibitor decreased oncolysis. Therefore, miR-204 levels showed significant associations with the NDV oncolytic effect. A similar phenomenon has been demonstrated in other oncolytic virus infections. Coxsackievirus-B3-induced apoptosis of cardiomyocytes is regulated by miR-34a (30). miR-31 and miR-128 modulate oncolytic measles virus infection and oncolysis through PVRL4 (31). Another study has shown that miR-99b and miR-485 function as enhancers of adenoviral oncolysis in pancreatic cancer (32). These results indicate that virus infection can change the miRNA expression profile in tumor cells and some miRNAs may participate in effective virus-triggered oncolysis. Previous studies have shown that potential mRNAs that were targeted by miR-204 were selected and identified to reveal various tumor-selective cell death pathways significantly associated with miRNA expression (33-35). At present, our group is performing transcriptome analysis of A549 cells infected by NDV. Data from further prediction algorithms and luciferase reporter constructs should be obtained to select potential target mRNAs. Additionally, the present results were obtained from in vitro experimental systems, so 
the miRNA regulation activity of NDV upon oncolytic activity should be demonstrated further in animal models.

Although the level of miR-204 was significantly associated with the NDV oncolytic effect, it was also found that miR-204 inhibitors or mimics had a limited effect on oncolysis. Cells have very strong compensatory mechanisms (36). Each gene may be targeted by hundreds of miRNAs, and each miRNA may regulate hundreds of genes (37). Therefore, this limited effect might be due to the existence of a large number of cellular regulatory factors, which can offset or mask the effect of inhibiting apoptosis.

Apoptosis consists of death receptor ligand/extrinsic and mitochondrial/intrinsic pathways. It has been confirmed that NDV induces tumor cell apoptosis through both of these pathways (38). The intrinsic and extrinsic pathways converge downstream at regulatory factor caspase-3, which is required to participate in tumor cell apoptosis induced by NDV (39). In the present study, miR-204 overexpression resulted in upregulation of full-length caspase-3, while inhibition via an miR-204 inhibitor decreased the level of full-length caspase-3. Therefore, miR-204 may regulate NDV oncolysis in A549 cells through the expression of full-length caspase-3. Activated initiator caspases subsequently free full-length caspase- 3 of their short inhibitory prodomain, allowing them to cleave a large set of cellular substrates (40). Therefore, not only full-length caspase-3, but also the levels of cleaved caspase-3 should be considered in future studies in order to demonstrate the role of caspase- 3 in the process of apoptosis. Bax, a member of the Bcl-2 family, is another signaling protein involved in apoptosis regulation by binding to the permeability transition pore complex, which is responsible for the regulation of mitochondrial membrane permeability. The present study also demonstrated that pharmacological inhibitors and mimics of miR-204 decreased and promoted the expression of Bax, respectively, in A549 cells, indicating that miR-204 regulates NDV oncolysis in A549 cells.

In summary, the present study provides preliminary evidence that NDV induces apoptosis in tumor cells via an miR-204-dependent pathway. miR-204 plays a role as a tumor suppressor in NDV-induced apoptosis in tumor cells. These findings indicate that the regulation of apoptosis signaling by miR-204 influences tumor survival in NDV-treated lung cancer. These results highlight the miRNA-regulatory activity of NDV upon oncolytic activity.

\section{Acknowledgements}

Not applicable.

\section{Funding}

This study was supported by a grant from the Natural Science Foundation of Guangxi, China (no. 2018GXNSFDA281043), the National Natural Science Foundation of China (no. 81960511) and the Guangxi First-class Discipline Project for Basic and Medicine Sciences (no. GXFCDP-BMS-2018).

\section{Availability of data and materials}

The datasets used and/or analyzed during the current study are available from the corresponding author on reasonable request.

\section{Authors' contributions}

YL contributed significantly to the statistical analysis and writing the manuscript. JJH performed the PCR and transfection experiments. WYT performed the western blotting and the apoptosis analysis. LXG performed the virus purification and cell cultures. XHF contributed to the study design and provided crucial experiment materials. YL, WYT, JJH, LXG and XHF confirm the authenticity of the raw data. All authors have read and approved the final manuscript.

\section{Ethics approval and consent to participate}

Not applicable.

\section{Patient consent for publication}

Not applicable.

\section{Competing interests}

The authors declare that they have no competing interests.

\section{References}

1. Sandler A, Gray R, Perry MC, Brahmer J, Schiller JH, Dowlati A, Lilenbaum R and Johnson DH: Paclitaxel-carboplatin alone or with bevacizumab for non-small-cell lung cancer. N Engl J Med 355: 2542-2550, 2006

2. Hirsch FR, Scagliotti GV, Mulshine JL, Kwon R, Curran WJ Jr, Wu YL and Paz-Ares L: Lung cancer: Current therapies and new targeted treatments. Lancet 389: 299-311, 2017.

3. Adam V, Dooms C and Vansteenkiste J: Lung cancer at the intensive care unit: The era of targeted therapy. Lung Cancer 89: 218-221, 2015.

4. Fournier P and Schirrmacher V: Oncolytic Newcastle disease virus as cutting edge between tumor and host. Biology (Basel) 2: 936-975, 2013

5. Lam HY, Yeap SK, Pirozyan MR, Omar AR, Yusoff K, Abd-Aziz S and Alitheen NB: Corrigendum to 'Safety and clinical usage of Newcastle disease virus in cancer therapy'. BioMed Res Int 2017: 4529437, 2017.

6. Batliwalla FM, Bateman BA, Serrano D, Murray D, Macphail S, Maino VC, Ansel JC, Gregersen PK and Armstrong CA: A 15-year follow-up of AJCC stage III malignant melanoma patients treated postsurgically with Newcastle disease virus (NDV) oncolysate and determination of alterations in the CD8 T cell repertoire. Mol Med 4: 783-794, 1998.

7. Cassel WA and Murray DR: A ten-year follow-up on stage II malignant melanoma patients treated postsurgically with Newcastle disease virus oncolysate. Med Oncol Tumor Pharmacother 9: 169-171, 1992.

8. Schirrmacher V, van Gool S and Stuecker W: Breaking therapy resistance: An update on oncolytic Newcastle disease virus for improvements of cancer therapy. Biomedicines 7: 66, 2019.

9. Cuadrado-Castano S, Sanchez-Aparicio MT, García-Sastre A and Villar E: The therapeutic effect of death: Newcastle disease virus and its antitumor potential. Virus Res 209: 56-66, 2015.

10. Keshavarz M, Nejad ASM, Esghaei M, Bokharaei-Salim F, Dianat-Moghadam H, Keyvani $\mathrm{H}$ and Ghaemi A: Oncolytic Newcastle disease virus reduces growth of cervical cancer cell by inducing apoptosis. Saudi J Biol Sci 27: 47-52, 2020.

11. Xu Q, Rangaswamy US, Wang W, Robbins SH, Harper J, Jin H and Cheng X: Evaluation of Newcastle disease virus mediated dendritic cell activation and cross-priming tumor-specific immune responses ex vivo. Int J Cancer 146: 531-541, 2020.

12. Jarahian M, Watzl C, Fournier P, Arnold A, Djandji D, Zahedi S, Cerwenka A, Paschen A, Schirrmacher V and Momburg F: Activation of natural killer cells by Newcastle disease virus hemagglutinin-neuraminidase. J Virol 83: 8108-8121, 2009.

13. Washburn B, Weigand MA, Grosse-Wilde A, Janke M, Stahl H, Rieser E, Sprick MR, Schirrmacher V and Walczak H: TNF-related apoptosis-inducing ligand mediates tumoricidal activity of human monocytes stimulated by Newcastle disease virus. J Immunol 170: 1814-1821, 2003. 
14. Koks CA, Garg AD, Ehrhardt M, Riva M, Vandenberk L, Boon L, De Vleeschouwer S, Agostinis P, Graf N and Van Gool SW: Newcastle disease virotherapy induces long-term survival and tumor-specific immune memory in orthotopic glioma through the induction of immunogenic cell death. Int J Cancer 136: E313-E325, 2015.

15. Ors-Kumoglu G, Gulce-Iz S and Biray-Avci C: Therapeutic microRNAs in human cancer. Cytotechnology 71: 411-425, 2019.

16. Li P, Wang Q and Wang H: MicroRNA-204 inhibits the proliferation, migration and invasion of human lung cancer cells by targeting PCNA-1 and inhibits tumor growth in vivo. Int J Mol Med 43: 1149-1156, 2019.

17. Guo W, Zhang Y, Zhang Y, Shi Y, Xi J, Fan H and Xu S: Decreased expression of miR-204 in plasma is associated with a poor prognosis in patients with non-small cell lung cancer. Int $\mathbf{J}$ Mol Med 36: 1720-1726, 2015.

18. Livak KJ and Schmittgen TD: Analysis of relative gene expression data using real-time quantitative PCR and the 2(-Delta Delta C(T)) method. Methods 25: 402-408, 2001

19. Ghrici M, El Zowalaty M, Omar AR and Ideris A: Induction of apoptosis in MCF-7 cells by the hemagglutinin-neuraminidase glycoprotein of Newcastle disease virus Malaysian strain AF2240. Oncol Rep 30: 1035-1044, 2013.

20. Li N, Guo X, Liu L, Wang L and Cheng R: Molecular mechanism of miR-204 regulates proliferation, apoptosis and autophagy of cervical cancer cells by targeting ATF2. Artif Cells Nanomed Biotechnol 47: 2529-2535, 2019.

21. Raihan J, Ahmad U, Yong YK, Eshak Z, Othman F and Ideris A: Regression of solid breast tumours in mice by Newcastle disease virus is associated with production of apoptosis related-cytokines. BMC Cancer 19: 315, 2019.

22. Ghosh S: Cisplatin: The first metal based anticancer drug. Bioorg Chem 88: 102925, 2019.

23. Dimitrov KM, Afonso CL, Yu Q and Miller PJ: Newcastle disease vaccines - A solved problem or a continuous challenge? Vet Microbiol 206: 126-136, 2017.

24. Yurchenko KS,Zhou P, Kovner AV,Zavjalov EL, Shestopalova LV and Shestopalov AM: Oncolytic effect of wild-type Newcastle disease virus isolates in cancer cell lines in vitro and in vivo on xenograft model. PLoS One 13: e0195425, 2018

25. Lazar I, Yaacov B, Shiloach T, Eliahoo E, Kadouri L, Lotem M, Perlman R, Zakay-Rones Z, Panet A and Ben-Yehuda D: The oncolytic activity of Newcastle disease virus NDV-HUJ on chemoresistant primary melanoma cells is dependent on the proapoptotic activity of the inhibitor of apoptosis protein Livin. J Virol 84: 639-646, 2010.

26. Al-Shammari AM, Salman MI, Saihood YD, Yaseen NY, Raed K, Shaker HK, Ahmed A, Khalid A and Duiach A: In vitro synergistic enhancement of Newcastle disease virus to 5-fluorouracil cytotoxicity against tumor cells. Biomedicines 4: 3, 2016.

27. Kalyanasundram J, Hamid A, Yusoff K and Chia SL: Newcastle disease virus strain AF2240 as an oncolytic virus: A review. Acta Trop 183: 126-133, 2018.
28. Zhang CX, Ye LW, Liu Y, Xu XY, Li DR, Yang YQ, Sun LL and Yuan J: Antineoplastic activity of Newcastle disease virus strain D90 in oral squamous cell carcinoma. Tumour Biol 36: 7121-7131, 2015

29. Zhang S, Gao L, Thakur A, Shi P, Liu F, Feng J, Wang T, Liang Y, Liu JJ, Chen M, et al: miRNA-204 suppresses human non-small cell lung cancer by targeting ATF2. Tumour Biol 37: 11177-11186, 2016.

30. Jiang D, Li M, Yu Y, Shi H and Chen R: microRNA-34a aggravates coxsackievirus B3-induced apoptosis of cardiomyocytes through the SIRT1-p53 pathway. J Med Virol 91: 1643-1651, 2019.

31. Geekiyanage H and Galanis E: MiR-31 and miR-128 regulates poliovirus receptor-related 4 mediated measles virus infectivity in tumors. Mol Oncol 10: 1387-1403, 2016.

32. Rovira-Rigau M, Raimondi G, Marín MA, Gironella M, Alemany R and Fillat C: Bioselection reveals miR-99b and miR-485 as enhancers of adenoviral oncolysis in pancreatic cancer. Mol Ther 27: 230-243, 2019.

33. Li T, Pan H and Li R: The dual regulatory role of miR-204 in cancer. Tumour Biol 37: 11667-11677, 2016.

34. Santoni G, Morelli MB, Santoni M, Nabissi M, Marinelli O and Amantini C: Targeting transient receptor potential channels by MicroRNAs drives tumor development and progression. Adv Exp Med Biol 1131: 605-623, 2020.

35. Tajbakhsh A, Mokhtari-Zaer A, Rezaee M, Afzaljavan F, Rivandi M, Hassanian SM, Ferns GA, Pasdar A and Avan A: Therapeutic potentials of BDNF/TrkB in breast cancer; current status and perspectives. J Cell Biochem 118: 2502-2515, 2017.

36. Wang X, Jia Y, Wang X, Wang C, Lv C, Li X, Chu Z, Han Q, Xiao S, Zhang S, et al: MiR-375 has contrasting effects on Newcastle disease virus growth depending on the target gene. Int J Biol Sci 15: 44-57, 2019.

37. Trobaugh DW and Klimstra WB: MicroRNA regulation of RNA virus replication and pathogenesis. Trends Mol Med 23: 80-93, 2017.

38. Bian J, Wang K, Kong X, Liu H, Chen F, Hu M, Zhang X, Jiao X, Ge B, Wu Y, et al: Caspase- and p38-MAPK-dependent induction of apoptosis in A549 lung cancer cells by Newcastle disease virus. Arch Virol 156: 1335-1344, 2011.

39. Yan Y,Liang B, Zhang J, Liu Y and Bu X: Apoptotic induction of lung adenocarcinoma A549 cells infected by recombinant RVG Newcastle disease virus (rL-RVG) in vitro. Mol Med Rep 11: 317-326, 2015.

40. Lamkanfi M and Kanneganti TD: Caspase-7: A protease involved in apoptosis and inflammation. Int J Biochem Cell Biol 42: 21-24, 2010. International (CC BY-NC-ND 4.0) License. 